\title{
Degradabilidade in situ e observações microscópicas de volumosos em bovinos suplementados com enzimas fibrolíticas exógenas ${ }^{1}$
}

\author{
Adriana de Souza Martins ${ }^{2}$, Paulo de Figueiredo Vieira ${ }^{3}$, Telma Teresinha Berchielli ${ }^{4}$, Ivanor \\ Nunes do Prado ${ }^{5}$, Beatriz Lempp ${ }^{6}$, Meiby Carneiro de Paula ${ }^{7}$ \\ ${ }_{1}$ Financiado pelo CNPq e parcialmente pela FUNDUNESP e ALLTECH do Brasil. \\ 2 Depto. de Ciências Agrárias do CESCAGE e Pesquisadora do IAPAR, Av. Euzébio de Queiroz, s/n CEP: 84001-970, Ponta Grossa/PR. \\ ${ }^{3}$ Curso de Zootecnia da UNIFENAS, Rod. MG 179, km 0 CEP: 37130-000, Alfenas/MG. \\ ${ }^{4}$ Faculdade de Ciências Agrárias e Veterinárias/UNESP, Rod. Carlos Tonnani km 5, CEP: 14870-000, Jaboticabal/SP. Pesquisador do CNPq \\ ${ }^{5}$ Depto. de Zootecnia da UEM, Pesquisador do CNPq. Av. Colombo, 5790, CEP: 87020-900. \\ ${ }^{6}$ Faculdade de Ciências Agrárias de Dourados, CX Postal 533 - CEP: 79804-970, Dourados/MS. \\ 7 IAPAR. Av. Euzébio de Queiroz, s/n CEP: 84001-970, Ponta Grossa/PR.
}

RESUMO - Avaliou-se o efeito de enzimas fibrolíticas (celulase e xilanase) sobre a degradabilidade in situ da MS, PB, FDN, FDA e hemicelulose do feno de Tifton-85 (Cynodon spp.) cortado aos 30 e 90 dias e do bagaço de cana, utilizando-se seis bovinos com cânula no rúmen. As enzimas foram extraídas dos fungos Aspergillus niger e Trichoderma longibrachiatum e fornecidas, na quantidade de 0,75 g/kgMS.dia, por meio da cânula ruminal. Os tempos de incubação ruminal foram de 0, 3, 6, 12, 24, 48, 72 e 96 horas. Os resíduos de incubação foram avaliados por meio de microscopia eletrônica de varredura (MEV). O efeito da adição de enzimas sobre a degradação da MS e PB variou em função do volumoso estudado. A degradabilidade efetiva da MS do feno Tifton cortado aos 30 e 90 dias e do bagaço de cana sem a adição de enzimas foi de 61,85; 42,35 e 28,22\%, respectivamente, e de 63,51; 40,64 e 31,43\%, respectivamente, com a adição das enzimas. Não houve efeito das enzimas sobre a degradação da fibra. As observações ao MEV indicaram aumento da colonização bacteriana sobre a parede celular com a suplementação enzimática. A adição de enzimas fibrolíticas na dieta de ruminantes apresentou efeito pouco expressivo sobre os parâmetros de degradação ruminal dos volumosos estudados.

Palavras-chave: celulase, fibra, microrganismos, ruminantes

\section{In situ degradability and microscopical observations of roughages in cattle supplemented with exogenous fibrolytic enzymes}

\begin{abstract}
The effect of fibrolytic enzymes addition (cellulase and xylanase) on the DM, CP, NDF, ADF, and hemicellulose in situ degradability of Tifton 85 hay (Cynodon spp.) cut at 30 and 90 days and sugarcane bagasse were evaluated with six bovines cannulated on the rumen. The enzymes were extracted from Aspergillus niger and Trichoderma longibrachiatum fungi and supplied $0.75 \mathrm{~g} / \mathrm{kg}$ of DM/animal.day, through ruminal cannula. The incubation times were 0 , 3, $6,12,24,48,72$, and 96 hours. The incubation residues were compared by scanning electron micrographs (SEM). The effect of enzyme addition on the DM and CP degradation varied in function of roughage studied. The effective degradability of DM of Tifton 85 hay cut at 30 and 90 days and sugarcane bagasse, without enzymes addition, was 61.85, 42.35, and 28.22\%, respectively, and 63.51, 40.64, and 31.43\%, respectively, with enzymes addition. There was no effect of enzymes on the fiber degradation. The SEM observations showed that bacterial colonization increased on the cell wall of roughages with enzymatic supplementation. The fibrolytic enzyme addition to the ruminant diet presented little expressive effect on the degradation parameters of studied roughages.
\end{abstract}

Key Words: cellulase, fiber, microrganisms, ruminants

\section{Introdução}

Os ruminantes são capazes de aproveitar volumosos de baixa qualidade de maneira eficiente, em virtude da síntese e secreção de enzimas celulolíticas e hemicelulolíticas pelos microrganismos do rúmen. Entretanto, o processo de digestão da forragem pode ser consideravelmente incompleto, especialmente quando se trata de forragens tropicais. Segundo Varga \& Kolver (1997), entre 20 e 70\% da celulose poderia não ser digerida e aproveitada pelo animal.

Com o objetivo de aumentar a eficiência de utilização dos alimentos pelos ruminantes, pesquisadores têm estudado o efeito da utilização de produtos biotecnológicos, destacando-se a suplementação com enzimas fibrolíticas 
exógenas compostas de celulase e hemicelulase. Estas enzimas, extraídas de fungos ou bactérias, em atuação conjunta com as enzimas produzidas pelos microrganismos ruminais, potencializam a degradação dos polissacarídeos estruturais e aumentam a taxa de degradação da fibra.

Os fungos aeróbios são fontes de enzimas comumente utilizadas na indústria de alimentos. A hidrólise da fibra por estes fungos consiste da liberação de enzimas no meio, promovendo a degradação do substrato. Este sistema difere do utilizado pelos microrganismos ruminais, que apresentam complexos multienzimáticos de células aderidas às partículas (celulossoma). Além disso, as enzimas provenientes de fungos suportam $\mathrm{pH}$ mais baixo que as enzimas ruminais (Morgavi et al., 2000).

Com base na hipótese de que nem todos os sítios do substrato disponíveis para a atuação das enzimas microbianas estejam ocupados, o aumento na concentração de enzimas fibrolíticas poderia incrementar a taxa de digestão da celulose e hemicelulose no rúmen, com o auxílio da atividade microbiana (Dehority \& Tirabasso, 1998).

Quanto ao modo de fornecimento das enzimas, estudos sugeriram que a administração diretamente no alimento seria mais eficaz que quando administradas no rúmen (McAllister et al., 1999). No entanto, Morgavi et al. (2000), avaliando o efeito de fontes de enzimas fibrolíticas incubadas in vitro com digesta ruminal de ovinos alimentados com feno de gramínea e concentrado, verificaram que a estabilidade das enzimas no fluido ruminal não foi fator limitante em sua atuação no alimento - resposta que pode ser enzimadependente, uma vez que houve variação na atividade enzimática entre as fontes.

A microscopia eletrônica de varredura (MEV) tem sido usada para visualizar e explicar os processos de degradação da parede celular pelos microrganismos do rúmen (Akin, 1989). A observação microscópica dos resíduos de degradação ruminal possibilita visualizar a intensidade de colonização microbiana nos diferentes tecidos da planta.

Objetivou-se com este trabalho avaliar o efeito da adição de enzimas fibrolíticas extraídas de fungos sobre a degradabilidade in situ do feno de Tifton 85 (Cynodon spp.) cortado aos 30 e 90 dias e do bagaço de cana-deaçúcar, em bovinos, e comparar a colonização microbiana dos resíduos de incubação por meio da microscopia eletrônica de varredura.

\section{Material e Métodos}

O experimento foi desenvolvido no Setor de Avaliação de Alimentos do Departamento de Zootecnia da Faculdade de Ciências Agrárias e Veterinárias -Campus de Jaboticabal/
UNESP-SP. Foram utilizados seis bovinos machos, castrados, providos de cânula no rúmen, com peso médio de $440 \mathrm{~kg}$, alojados em baias individuais cobertas, com comedouro e bebedouro. Avaliou-se o efeito da adição de enzimas fibrolíticas exógenas sobre a degradação ruminal in situ do feno de Tifton 85 (Cynodon spp) cortado aos 30 e 90 dias e do bagaço de cana-de-açúcar. Foram utilizados três animais como repetição, ou seja, três animais consumiram a dieta basal com a adição das enzimas via cânula ruminal e três consumiram a mesma dieta sem a adição das enzimas.

As dietas foram formuladas com base na ingestão de energia metabolizável fermentável e de proteína degradável no rúmen, segundo as recomendações do AFRC (1995). A proporção volumoso concentrado foi de $70: 30$, sendo o concentrado composto de milho e levedura e o volumoso de silagem de milho, bagaço de cana, palha de arroz e feno de Tifton cortado aos 30 e 90 dias. A composição percentual (\% MS) dos ingredientes da dieta foi de 11,7; 18,3 e 14\%, respectivamente, para o milho, a levedura e cada volumoso. A dieta total (volumoso + concentrado) foi fornecida duas vezes ao dia (8 e 15h), sendo fornecido aproximadamente 2,5\% do PV (Tabela 1$)$.

As enzimas fibrolíticas utilizadas foram provenientes de fonte comercial (Fibrozyme - ALLTECH - Empresa Biotecnológica de Produção Animal.) e extraídas dos fungos Aspergillus niger e Trichoderma longibrachiatum. $\mathrm{O}$ produto constituiu de celulase e xilanase e de um surfactante (extrato de Yucca echtigera), veículo que tem a função de aumentar o contato das enzimas com o substrato.

A atividade enzimática do Fibrozyme, obtida a $39^{\circ} \mathrm{C}$ e $\mathrm{pH}$ 4,0, foi de aproximadamente 100 unidades de xilanase (UX) por grama do produto. Uma unidade de xilanase corresponde à quantidade de enzima requerida para liberar um micromol de xilose (substrato). Foi fornecido $0,75 \mathrm{~g}$ de Fibrozyme/kg de MS/animal/dia, segundo recomendações do fabricante. O complexo enzimático foi acondicionado em cápsulas de papel e fornecido, às $8 \mathrm{~h}$, via cânula ruminal.

Os volumosos foram processados em peneira com crivos de $5 \mathrm{~mm}$ e acondicionadas em bolsas de náilon $(7 \times 14 \mathrm{~cm}$, $50 \mathrm{~mm}$ de tamanho de poros) nos seguintes tempos de incubação: 0, 3, 6, 12, 24, 48, 72 e 96 horas, em duplicata. Foram incubados 4,5 g de cada volumoso (base na MS). O complexo enzimático também foi inserido nas bolsas de náilon para incubação, em todos os tempos, em proporção similar à recomendada. Ao final de cada tempo de incubação, as bolsas foram lavadas em máquina de lavar durante 30 minutos e, posteriormente, submetidas à secagem em estufa com ventilação forçada a $65^{\circ} \mathrm{C}$, por 72 horas. Os resíduos foram analisados quanto aos teores de MS e PB, 
Tabela 1- Composição química dos ingredientes da dieta (\% MS)

Table 1 - Chemical composition of the dietary ingredients (\% DM)

\begin{tabular}{lcccrr}
\hline $\begin{array}{l}\text { Ingrediente } \\
\text { Ingredient }\end{array}$ & MS (\%) & PB (\%) & FDN (\%) & FDA (\%) & Hem (\%) \\
ADF & $\begin{array}{c}\text { NIDA/Ntotal } \\
\text { ADIN/total N }\end{array}$ \\
\hline Silagem de milho (Corn silage) & 32 & 7,74 & 46,28 & 24,32 & 21,96 \\
Bagaço de cana (Sugarcane bagasse) & 43 & 1,21 & 85,12 & 64,72 & 20,40 \\
Palha de arroz (Rice straw) & 92 & 6,52 & 67,20 & 40,63 & 26,57 \\
Feno de Tifton30 (Tifton hay30) & 92 & 8,75 & 69,96 & 34,58 & 35,38 \\
Feno de Tifton 902 (Tifton hay30) & 92 & 5,55 & 79,76 & 42,99 & 36,79 \\
Milho (Corn) & 90 & 12,00 & 12,02 & 5,16 & 4,31 \\
Levedura (Yeast) & 89 & 37,80 & - & - & $-6,86$ \\
\hline
\end{tabular}

NIDA/Ntotal = Nitrogênio insolúvel em detergente ácido/Ntotal (Acid detergent insoluble nitrogen/total N).

${ }^{1}$ Coletado aos 30 dias de rebrota.

2 Coletado aos 90 dias de rebrota.

1 Cut at 30 days.

2 Cut at 90 days

pelo método de combustão de Dumas, utilizando o analisador de Nitrogênio Leco FP-528, e FDN, FDA e nitrogênio insolúvel em detergente ácido (NIDA), pelo método descrito por Silva \& Queiroz (2002), utilizando o analisador de fibras ANKOM. A hemicelulose foi calculada pela diferença entre FDN e FDA.

Os dados sobre o desaparecimento da MS, PB, FDN, FDA e hemicelulose dos volumosos foram ajustados por uma regressão não-linear, por meio do modelo proposto por Mehrez \& Ørskov (1977): p = a + b(1- - $\left.\mathrm{e}^{-\mathrm{kd} t}\right)$, em que p corresponde à degradação no tempo t; “a”, à fração solúvel; "b”, à fração potencialmente degradável; $\mathrm{k}_{\mathrm{d}}$, à taxa de degradação da fração b; e $t$, ao tempo de incubação em horas.

A degradabilidade efetiva (DE) foi calculada segundo o modelo proposto por Ørskov \& Mc Donald (1979): DE = $\mathrm{a}+\left(\left(\mathrm{b} . \mathrm{k}_{\mathrm{d}}\right) /\left(\mathrm{k}_{\mathrm{d}}+\mathrm{k}_{\mathrm{p}}\right)\right)$

em que $\mathrm{k}_{\mathrm{p}}$ equivale à taxa estimada de passagem de sólidos no rúmen por hora. Foi considarada a taxa de passagem de sólidos no rúmen de 2\%/h (ARC, 1984). A fração indegradável (C) foi obtida pela equação: $\mathrm{C}=100-(\mathrm{a}+\mathrm{b})$.

Para as análises de microscopia eletrônica de varredura (MEV), foi inserida no rúmen uma bolsa extra para cada tempo de incubação. Depois de retirados do rúmen, os resíduos foram processados, segundo Santos (1996), no Laboratório de Microscopia Eletrônica e analisados por meio de elétron-micrografias de varredura (Lempp, 1997). Com base nesta metodologia, o resíduo foi fixado em solução de glutaraldeído a 3\%, em solução tampão (cacodilato de potássio 0,05 M), e mantido sob refrigeração; após, foi fixado em tetróxido de ósmio a 1\% na mesma solução tampão e seco (secador de ponto crítico - Tousimis Samdri PVT3). Posteriormente, os espécimes foram montados em cilindros de alumínio metalizados, com uma camada de ouro-paládio (JEOL JFC1100) e avaliados por meio de observação no microscópio eletrônico de varredura (MEV), marca JEOL, modelo JSM5410, utilizando-se para as elétron-micrografias o filme ILFORD FP4 (ISSO $125 / 22^{\mathrm{O}}$ ).

O delineamento experimental foi o inteiramente casualizado, em parcelas subdivididas, em que os “tempos" de incubação constituíram as parcelas e os volumosos e a adição ou não de enzimas, as subparcelas. O tempo para atingir a DP foi determinado utilizando o teste de comparações múltiplas (contraste de Hamlert). A análise de variância e a comparação de médias pelo teste Tukey, a 5\% de significância, foram determinadas pelo SAS (1997).

\section{Resultados e Discussão}

Não houve efeito $(\mathrm{P}>0,05)$ da adição de enzimas sobre os parâmetros de degradação ruminal da MS do feno de Tifton85 cortado aos 30 e 90 dias (Tabela 2). A fração solúvel da MS do feno de Tifton-85 cortado em ambas as idades foi superior ao valor de 5,2\%, encontrado por Ítavo et al. (2002). De modo geral, os valores obtidos para a fração solúvel de ambos os fenos foram elevados, podendo ter ocorrido perda de material durante a determinação desta fração.

Os valores médios obtidos para a DE da MS e FDN (62,7 e 53\%, respectivamente) do feno de Tifton cortado aos 30 dias foram superiores aos encontrados por Assis et al. (1998), de 55 e 51\%, respectivamente, com taxa de passagem de $2 \% / h$. Ítavo et al. (2002), avaliando a degradabilidade de fenos de gramíneas do gênero Cynodon, observaram valores para a DE da MS e PB do feno de Tifton 85 de 49,88 e $67,11 \%$, com taxa de passagem de $2 \% / \mathrm{h}$, sendo inferiores e superiores, respectivamente, aos obtidos nesta pesquisa para o feno de Tifton-85 cortado aos 30 e 90 dias. As variações nos parâmetros de degradação ruminal ocorreram, provavelmente, em função das diferenças na idade de colheita dos fenos estudados.

Houve aumento $(\mathrm{P}<0,05)$ da fração solúvel da PB do feno de Tifton-85 cortado aos 30 dias com a suplementação 
Tabela 2 - Estimativas das frações solúvel (a), potencialmente degradável (b) e indegradável (C), taxa de degradação ( $\left.k_{d}\right)$, degradação potencial (DP) e degradação efetiva (DE) de MS e PB dos volumosos sem (SE) e com (CE) a adição de enzimas fibrolíticas

Table 2 - Estimates of soluble fractions (a), potentially degradable (b) and indigestible (C), degradation rate ( $\left.k_{d}\right)$, potential degradation (PD), and effective degradation (ED) of DM and CP of forages without (-FE) and with (+FE) fibrolytic enzymes addition

\begin{tabular}{|c|c|c|c|c|c|c|}
\hline \multirow[t]{2}{*}{ Item } & \multicolumn{2}{|c|}{$\begin{array}{c}\text { FT30 }^{1} \\
\text { TH30 }\end{array}$} & \multicolumn{2}{|c|}{$\begin{array}{c}\text { FT90 } \\
\text { TH90 }\end{array}$} & \multicolumn{2}{|c|}{$\begin{array}{c}\mathrm{BC}^{3} \\
S B^{3}\end{array}$} \\
\hline & $\begin{array}{l}\mathrm{SE} \\
-F E\end{array}$ & $\begin{array}{c}\text { CE } \\
+F E\end{array}$ & $\begin{array}{l}\mathrm{SE} \\
-F E\end{array}$ & $\begin{array}{l}\text { CE } \\
+F E\end{array}$ & $\begin{array}{l}\mathrm{SE} \\
-F E\end{array}$ & $\begin{array}{c}\text { CE } \\
+F E\end{array}$ \\
\hline & \multicolumn{6}{|c|}{$\mathrm{MS}(D M)$} \\
\hline a & 21,61 & 23,13 & 14,55 & 12,76 & 5,27 & 4,62 \\
\hline b & 55,04 & 53,67 & 39,74 & 42,69 & $33,27 b$ & $42,57 \mathrm{a}$ \\
\hline $\mathrm{k}_{\mathrm{d}}(\% / \mathrm{h})$ & 5,57 & 6,09 & 4,76 & 3,88 & 4,63 & 3,50 \\
\hline $\mathrm{C}$ & 23,35 & 23,20 & 45,71 & 44,55 & $61,46 a$ & $52,81 b$ \\
\hline DP & 76,65 & 76,80 & 54,29 & 55,45 & $38,54 b$ & $47,19 \mathrm{a}$ \\
\hline \multirow[t]{2}{*}{$\mathrm{DE}^{4}$} & 61,85 & 63,51 & 42,35 & 40,64 & 28,22 & 31,43 \\
\hline & \multicolumn{6}{|c|}{$\mathrm{PB}(C P)$} \\
\hline $\mathrm{a}$ & $30,73 b$ & $34,52 \mathrm{a}$ & 44,72 & 44,35 & $1,58 b$ & $6,78 a$ \\
\hline b & 59,57 & 56,76 & 31,85 & 30,69 & $12,29 a$ & $5,72 b$ \\
\hline $\mathrm{k}_{\mathrm{d}}(\% / \mathrm{h})$ & 5,38 & 5,04 & 1,56 & 2,74 & 0,42 & 0,59 \\
\hline $\mathrm{C}$ & 9,70 & 8,72 & 23,43 & 24,95 & 86,14 & 87,5 \\
\hline DP & 90,30 & 91,28 & $70,44 b$ & $75,04 a$ & 13,87 & 12,50 \\
\hline $\mathrm{DE}^{4}$ & 74,06 & 75,12 & $55,02 b$ & $62,04 \mathrm{a}$ & 3,21 & 7,98 \\
\hline
\end{tabular}

${ }^{1}$ Feno de Tifton 85 cortado aos 30 dias.

2 Feno de Tifton 85 cortado aos 90 dias.

3 Bagaço de cana.

${ }^{4}$ Considerando taxa de passagem de $2 \% / h$. Médias seguidas de letras diferentes na linha, dentro de cada fonte de volumoso, diferem (P<0,05) pelo teste Tukey.

1 Tifton 85 hay cutted at 30 days.

2 Tifton 85 hay cutted at 90 days.

3 Sugarcane bagasse.

${ }^{4}$ Considering passage rate of $2 \% / h$. Means followed by different letters in the same row, within each roughage source, differ $(P<0.05)$ by Tukey test.

enzimática, entretanto, para os demais parâmetros da degradação deste feno, a adição de enzimas não causou efeito ( $P>0,05)$. O aumento da fração solúvel significa, necessariamente, que o nitrogênio solúvel seja degradado no rúmen. De acordo com o NRC (2001), as proteínas solúveis não são igualmente susceptíveis à degradação ruminal e podem deixar o rúmen rapidamente, devido à maior associação com a porção líquida do conteúdo ruminal. Neste sentido, Sniffen et al. (1992) relataram que a relação entre solubilidade e degradabilidade da proteína será maior quando grande parte do nitrogênio solúvel estiver na forma de nitrogênio não-protéico (NNP).

A degradação da PB do feno de Tifton cortado aos 90 dias sofreu efeito da ação enzimática no rúmen, comprovado pelo aumento $(\mathrm{P}<0,05)$ da $\mathrm{DP}$ e $\mathrm{DE}$ com a suplementação enzimática, mostrando que a atuação das enzimas depende da estrutura químico-morfológica da forragem. Morgavi et al. (2000) observaram a ocorrência de sinergia entre as enzimas exógenas extraídas de fungo e as enzimas microbianas, durante o processo de hidrólise da celulose e da xilose. Portanto, é provável que as enzimas exógenas tenham influenciado o ataque microbiano sobre a fibra.

O bagaço de cana-de-açúcar (BC) sem a adição de enzimas apresentou valores de 5,27\%, 4,63\%/h e 38,54\%, respectivamente, para a fração solúvel, taxa de degradação e DP da MS, sendo superiores aos obtidos por Deschamps (1994), de 2,81\%, 1,4\%/h e 30,9\%, respectivamente. A suplementação enzimática influiu nos parâmetros de degradação ruminal do BC. A adição de enzimas aumentou a fração "b" e reduziu a fração C da MS deste volumoso $(\mathrm{P}<0,05)$. Houve aumento da fração "a” e redução da fração "b" da PB com a adição das enzimas $(\mathrm{P}<0,05)$, porém, estas frações são pouco significativas, em razão do baixo teor de proteína do bagaço.

O complexo enzimático prolongou o tempo de degradação da PB do BC, de 72 (SE) para 96 horas (CE), e da MS, de 48 (SE) para 96 horas (CE), com aumento da DP da MS de 38,5 para 47,2\% $(\mathrm{P}<0,05)$. O maior teor de fibra do BC pode ter disponibilizado maior número de sítios de degradação para a atuação enzimática, de origem microbiana ou do próprio suplemento.

Não houve efeito $(\mathrm{P}>0,05)$ da adição de enzimas sobre a degradação ruminal da parede celular de ambos os fenos (Tabela 3). Segundo Coughlan (1990), durante o processo de degradação, em decorrência da estabilidade da fração cristalina da celulose, as ligações clivadas pelas endoglucanases poderiam ser novamente formadas de maneira espontânea, em função da ausência de celobioidrolase, evidenciando a 
interação sinergística de endo e exo-enzimas. Desta forma, em função da composição químico-morfológica da forragem e do requerimento de enzimas específicas para a degradação da fibra, a adição de enzimas fibrolíticas pode ter alterado a proporção de endo e exo-enzimas, dificultando a interação de ambas e comprometendo a atuação de determinadas enzimas sobre a degradação dos componentes da parede celular.

Outra possível explicação para a ausência do efeito das enzimas exógenas sobre a fibra seria o teor de aplicação das mesmas. Yang et al. (1999) relataram que o nível de adição de complexos enzimáticos abaixo de $1 \mathrm{~g} / \mathrm{kg}$ de MS, como verificado neste estudo, não causa efeito sobre a degradação da fibra no rúmen.

Beauchemin et al. (1995), avaliando o efeito de níveis de aplicação de enzimas fibrolíticas em diferentes volumosos, verificaram que a concentração das enzimas e a resposta animal (consumo, ganho em peso e digestibilidade) apresentaram comportamento quadrático, indicando a existência de um nível ótimo de aplicação para os diferentes volumosos. Outro fator responsável pela eficiência do complexo enzimático seria o modo de aplicação do mesmo no alimento.

O feno de Tifton-85 cortado aos 30 apresentou maior DE da FDN, FDA e hemicelulose que o cortado aos 90 dias $(\mathrm{P}<0,05)$. Forragens jovens apresentam menores concentrações de lignina core, a qual está negativamente correlacionada à digestibilidade (Jung \& Deetz, 1990), havendo menor resistência física (menor lignificação) da parede celular de fenos com menor idade de corte.

Observou-se maior efeito da adição de enzimas na parede celular do BC. A taxa de degradação (kd) da FDN deste volumoso diminuiu com a suplementação enzimática $(\mathrm{P}<0,05)$. Na medida em que ocorreu a degradação da parede celular, observou-se aumento da proporção de lignina com relação à matriz fibrosa, o que, de acordo com Gilbert \& Hazlewood (1993), dificultaria o reconhecimento do sítio catalítico das enzimas fibrolíticas pelo substrato, resultando na redução da taxa de degradação.

Por outro lado, houve aumento da fração b e redução da fração indigestível da hemicelulose com a adição do suplemento $(\mathrm{P}<0,05)$. Constatou-se aumento $(\mathrm{P}<0,05)$ da DP

Tabela 3 - Estimativas das frações solúvel (a), potencialmente degradável (b) e indegradável (C), taxa de degradação ( $\left.k_{d}\right)$, degradação potencial (DP) e degradação efetiva (DE) da FDN e FDA dos volumosos sem (SE) e com (CE) a adição de enzimas fibrolíticas

Table 3 - Estimates of soluble fractions (a), potentially degradable (b) and indigestible (C), degradation rate (kd), potential degradation (PD) and effective degradation (ED) of NDF, ADF, and hemicellulose of forages without ( $-F E)$ and with ( $+F E)$ fibrolytic enzymes addition

\begin{tabular}{|c|c|c|c|c|c|c|}
\hline \multirow[t]{2}{*}{ Item } & \multicolumn{2}{|c|}{$\begin{array}{c}\text { FT30 } \\
\text { TH } 30^{1}\end{array}$} & \multicolumn{2}{|c|}{$\begin{array}{c}{\text { FT } 90^{2}}^{2} \\
\text { TH90 }^{2}\end{array}$} & \multicolumn{2}{|c|}{$\begin{array}{l}\mathrm{BC}^{3} \\
\mathrm{SB}^{3}\end{array}$} \\
\hline & $\begin{array}{l}\mathrm{SE} \\
-F E\end{array}$ & $\begin{array}{c}\text { CE } \\
+F E \\
\end{array}$ & $\begin{array}{l}\text { SE } \\
-F E\end{array}$ & $\begin{array}{c}\text { CE } \\
+F E\end{array}$ & $\begin{array}{l}\text { SE } \\
-F E\end{array}$ & $\begin{array}{c}\text { CE } \\
+F E\end{array}$ \\
\hline & \multicolumn{6}{|c|}{ FDN (NDF) } \\
\hline b & 71,24 & 70,75 & 50,02 & 51,12 & 31,33 & 40,30 \\
\hline $\mathrm{k}_{\mathrm{d}}(\% / \mathrm{h})$ & 5,82 & 6,20 & 4,36 & 3,80 & $4,92 \mathrm{a}$ & $2,71 b$ \\
\hline $\mathrm{C}$ & 28,76 & 29,25 & 49,98 & 48,88 & 68,67 & 59,70 \\
\hline DP & 71,24 & 70,75 & 50,02 & 51,12 & 31,33 & 40,30 \\
\hline \multirow[t]{2}{*}{$\mathrm{DE}^{4}$} & 52,59 & 53,38 & 34,11 & 33,14 & 22,54 & 23,12 \\
\hline & \multicolumn{6}{|c|}{ FDA $(A D F)$} \\
\hline b & 69,11 & 69,67 & 48,65 & 47,85 & 39,34 & 40,06 \\
\hline $\mathrm{k}_{\mathrm{d}}(\% / \mathrm{h})$ & 5,47 & 5,59 & 4,39 & 3,71 & 3,08 & 2,58 \\
\hline $\mathrm{C}$ & 30,89 & 30,33 & 51,35 & 52,15 & 60,66 & 59,94 \\
\hline DP & 69,11 & 69,67 & 48,65 & 47,85 & 39,34 & 40,06 \\
\hline \multirow[t]{2}{*}{$\mathrm{DE}^{4}$} & 50,26 & 50,76 & 33,14 & 30,74 & 25,30 & 22,47 \\
\hline & \multicolumn{6}{|c|}{ Hemicelulose (Hemicellulose) } \\
\hline $\mathrm{b}$ & 73,26 & 74,87 & 50,42 & 52,90 & $38,04 b$ & $49,07 a$ \\
\hline $\mathrm{k}_{\mathrm{d}}(\% / \mathrm{h})$ & 5,24 & 5,11 & 4,67 & 4,36 & 3,13 & 2,99 \\
\hline $\mathrm{C}$ & 26,74 & 25,13 & 49,58 & 47,10 & $61,96 a$ & $50,93 b$ \\
\hline DP & 73,26 & 74,87 & 50,42 & 52,90 & $38,04 b$ & $49,07 a$ \\
\hline $\mathrm{DE}^{4}$ & 52,84 & 52,94 & 35,23 & 36,15 & 22,63 & 28,90 \\
\hline
\end{tabular}

${ }^{1}$ Feno de Tifton 85 cortado aos 30 dias.

${ }^{2}$ Feno de Tifton 85 cortado aos 90 dias.

3 Bagaço de cana.

${ }^{4}$ Considerando taxa de passagem de $2 \% / h$. Médias seguidas de letras diferentes na linha, dentro de cada fonte de volumoso, diferem (P<0,05) pelo teste Tukey.

1 Tifton 85 hay cutted at 30 days

2 Tifton 85 hay cutted at 90 days.

${ }^{3}$ Sugarcane bagasse.

${ }^{4}$ Considering passage rate of $2 \% / h$. Means followed by different letters in the same row, within each roughage source, differ (P<0.05) by Tukey test. 
da hemicelulose com o uso de enzimas exógenas, o qual foi acompanhado do prolongamento do tempo para atingir a DP, de 48 h (SE) e 96 h (CE). O mesmo ocorreu com a FDN, que passou de 48 para $72 \mathrm{~h}$ para atingir a DP, com a adição do suplemento. Este resultado sugere que o incremento enzimático (celulase e xilanase) ocorrido no rúmen teria potencializado a ação das enzimas microbianas sobre as ligações entre a lignina, celulose e hemicelulose. Rode et al. (1999) sugeriram que a hidrólise da fibra no rúmen pelas enzimas fibrolíticas exógenas não seria somente de forma direta, mas também pelo aumento gradual da atividade das enzimas microbianas no rúmen.

Ishii (1997) isolou do bagaço de cana o trissacarídeo feruloil-arabinoxilana e verificou que a digestão da parede celular pelos microrganismos do rúmen depende da natureza das ligações entre os polissacarídeos e derivados do ácido hidroxicinâmico, dentre eles, o p-coumárico e ferúlico. Assim, a ação das xilanases sobre a hemicelulose pode ter rompido estas ligações, facilitando a degradação microbiana da fibra do bagaço.

Desta forma, com relação à degradação da fibra, verificou-se maior efeito das enzimas exógenas sobre o bagaço de cana. Este efeito pode estar relacionado à baixa qualidade deste volumoso, que apresenta maior disponibilidade de substrato fibroso, tornando mais evidente a atuação das enzimas fibrolíticas.

Embora a fração indegradável (C) da PB do feno de Tifton-85 cortado aos 30 dias não tenha sido alterada com a adição das enzimas (Tabela 2), quando expressa em \% do $\mathrm{N}$ total, o teor de NIDA foi reduzido com a adição do suplemento enzimático. Este efeito sugere que a presença de uma fonte extra de enzimas celulolíticas e hemicelulolíticas no rúmen poderia ter melhorado a disponibilidade ruminal do N ligado à parede celular deste feno. Segundo Iiyama (1993), existem três classes de proteínas ligadas à parede celular: glicoproteína rica em hidroxiprolina (extensinas), proteína rica em glicina e proteína rica em prolina.

Neste sentido, Hatfield (1989) comentou que a extensina foi normalmente encontrada aderida aos resíduos insolúveis da parede celular, especialmente à celulose. Portanto, o aumento na concentração de celulases no rúmen pode ter promovido a liberação das extensinas ligadas à celulose, reduzindo o teor de nitrogênio ligado à fibra (NIDA).

A adição de enzimas ao feno de Tifton 85 cortado aos 90 dias não alterou o teor de NIDA/N total dos resíduos de incubação (Figura 1A). Houve redução do teor de NIDA com o tempo de incubação, indicando a perda de parede celular e de NIDA contidos nos resíduos incubados. Além disso, pode ter ocorrido contaminação dos resíduos de
A
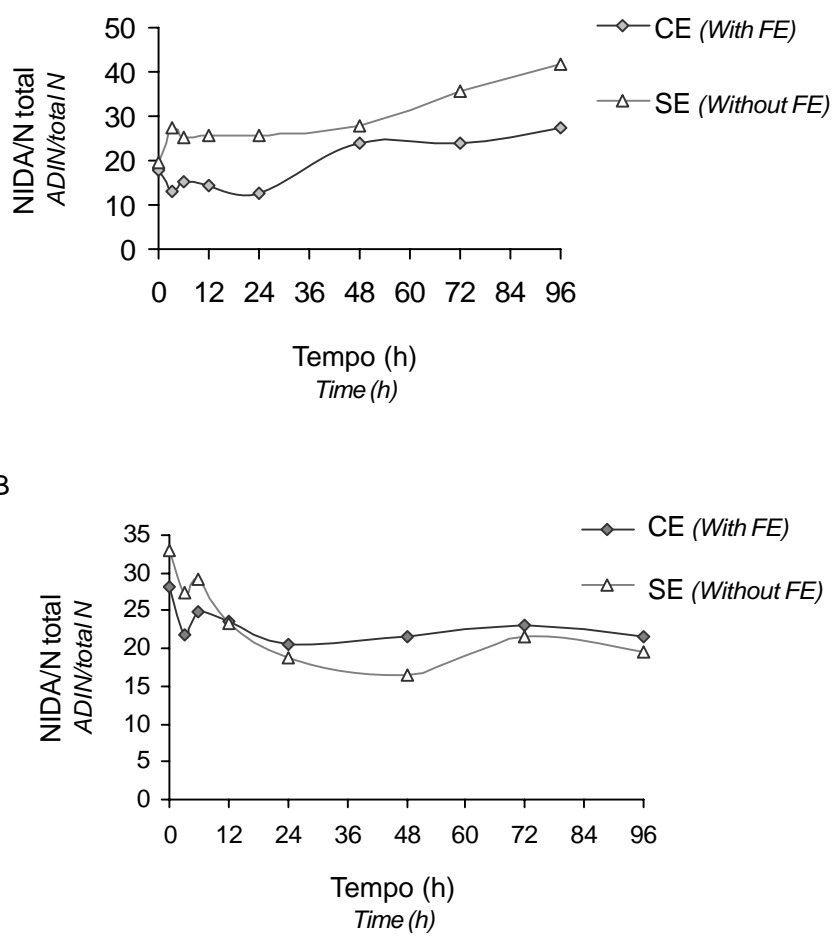

Figura 1 - Teores de nitrogênio insolúvel em detergente ácido em relação ao nitrogênio total (NIDA/N total), em função dos tempos de incubação do feno de Tifton 85 cortado aos 30 (A) e 90 (B) dias sem (SE) e com (CE) adição de enzimas fibrolíticas.

Figure 1 - Levels of acid detergent insoluble nitrogen in relation to the total nitrogen (ADIN/total $N$ ), on the incubation times of Tifton 85 hay cut at 30 days without and with fibrolytic enzymes (FE) addition.

incubação com $\mathrm{N}$ bacteriano, causando aumento do $\mathrm{N}$ total e, conseqüentemente, reduzindo a relação NIDA/N total. A ausência do efeito da suplementação enzimática no F90 pode ser atribuída ao menor teor de proteína deste feno, que teria reduzido o efeito da atividade enzimática sobre a relação NIDA/N total.

A relação NIDA/N total dos resíduos de incubação do bagaço de cana (Figura 2) foi alta quando comparada à dos demais volumosos, provavelmente em razão do elevado teor de fibra (85,12\% de FDN e 64,72\% de FDA) e do baixo teor de proteína (1,21\%).

A adição de enzimas fibrolíticas ao bagaço de cana-deaçúcar também não alterou o teor de NIDA deste volumoso (Figura 2), concordando com os dados de degradação da PB (Tabela 2), em que a suplementação enzimática não causou diferença da fração C da PB do bagaço de cana.

As observações ao microscópio eletrônico de varredura (MEV) dos resíduos de digestão do feno de Tifton-85 cortado aos 30 dias sem enzimas, com 12 horas de incubação 


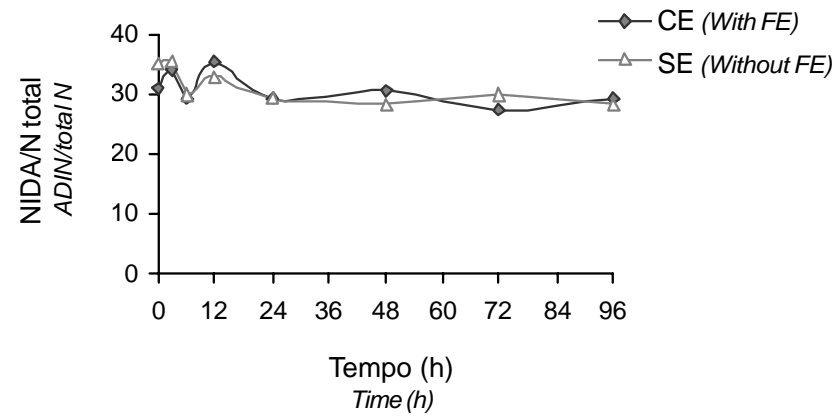

Figura 2 - Teores de nitrogênio insolúvel em detergente ácido em relação ao nitrogênio total (NIDA/N total), em função dos tempos de incubação do bagaço de canade-açúcar sem (SE) e com (CE) adição de enzimas fibrolíticas.

Figure 2 - Levels of acid detergent insoluble nitrogen in relation to the total nitrogen (ADIN/total $N$ ), on the incubation times of sugarcane bagasse without and with fibrolytic enzymes (FE) addition.
(Figura 3A), indicaram a presença de colônias de bactérias na epiderme, entretanto, não houve exposição da parede celular secundária destas células. Por outro lado, nos resíduos incubados com enzimas (Figura 3B), observou-se a exposição da parede celular secundária, que se apresentou parcialmente digerida pelas bactérias.

O resíduo de digestão do feno de Tifton-85 cortado aos 30 dias após 48 horas de degradação sem a suplementação enzimática (Figura 3C) não apresentou células do mesofilo, observando-se pouca colonização nas células da bainha parenquimática dos feixes vasculares (BPFV). Neste resíduo (Figura 3D), a adição de enzimas indicou a presença de bactérias aderidas à BPFV, mostrando-se parcialmente digerida.

As observações ao MEV do resíduo de digestão (3 h) do feno de Tifton-85 cortado aos 90 dias, sem a adição de enzimas (Figura 4A), revelaram a epiderme danificada e
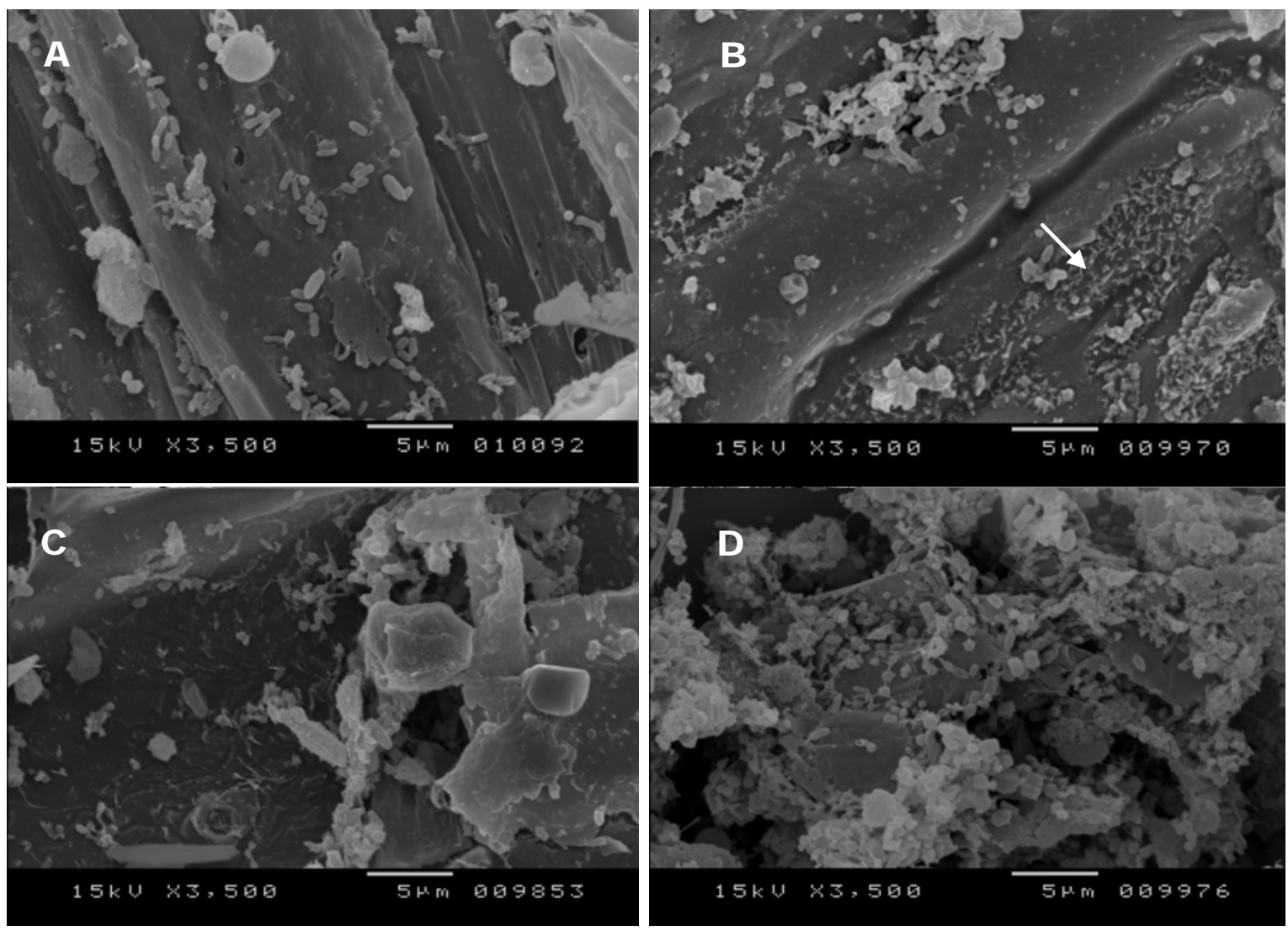

Figura 3 - Elétron-micrografias de varredura dos resíduos de degradação in situ do feno de Tifton 85 cortado aos 30 dias (FT30) sem a adição de enzimas ( $A$ e $C$ ) e com a adição de enzimas fibrolíticas (B e D). A e B - 12 horas de incubação; C e D - 48 horas de incubação. 4B ${ }^{\circledR}$ exposição da parede celular secundária.

Figure 3 - Scanning electron micrograph of in situ degradation residues of Tifton 85 hay cutted at 30 days without enzymes addition ( $A$ and $C$ ) and with fibrolytic enzyme addition ( $B$ and $D)$. $A$ and $B-12$ hours of incubation. $C$ and $D-48$ hours of incubation. $4 B \otimes$ secundary cell wall exposition. 
exposição da célula de mesofilo com menor colonização e digestão, comparada ao resíduo deste feno com a adição de enzimas (Figura 4B). Este, porém, apresentou célula de mesofilo colonizada e praticamente digerida.

Akin \& Burdick (1975) relataram que as células do mesofilo poderiam ser digeridas parcialmente por enzimas extracelulares, portanto, as enzimas fibrolíticas exógenas podem ter contribuído para a digestão destas células.

As observações do MEV dos resíduos após 48 horas de digestão do BC sem a suplementação enzimática indicam baixa colonização de bactérias (Figura 5A). No entanto, a adição de enzimas ao BC promoveu aumento da colonização microbiana nos resíduos após 48 horas de incubação, porém sem sinais de degradação do tecido. Os resíduos de digestão do bagaço incubado por 72 horas, sem a adição de enzimas, indicaram baixa colonização microbiana e epiderme danificada. As observações microscópicas dos resíduos com a adição de enzimas revelaram a presença de bactérias e células do esclerênquima ainda intactas (Figura 5D).
Segundo Wilson \& Mertens (1995), estas células são digeridas do lúmen para a superfície, graças à proteção da lamela média primária indigestível. Além disso, estas células apresentam pequena área de superfície para colonização bacteriana em relação à quantidade de parede celular a ser digerida.

De modo geral, as elétron-micrografias de varredura dos volumosos estudados indicaram aumento da colonização microbiana sobre os diferentes tecidos com a adição de enzimas fibrolíticas. Entretanto, estes resultados não foram condizentes com os parâmetros de degradação ruminal dos volumosos estudados, mostrando que o aumento na colonização e digestão dos tecidos observados ao MEV, com a adição de enzimas, não foi suficiente para gerar uma resposta efetiva sobre a degradação ruminal da fibra, com exceção do bagaço de cana.

A ausência de resposta da suplementação enzimática pode estar relacionada, entre outros fatores, à quantidade de enzimas fornecida ao animal e ao tipo de forragem
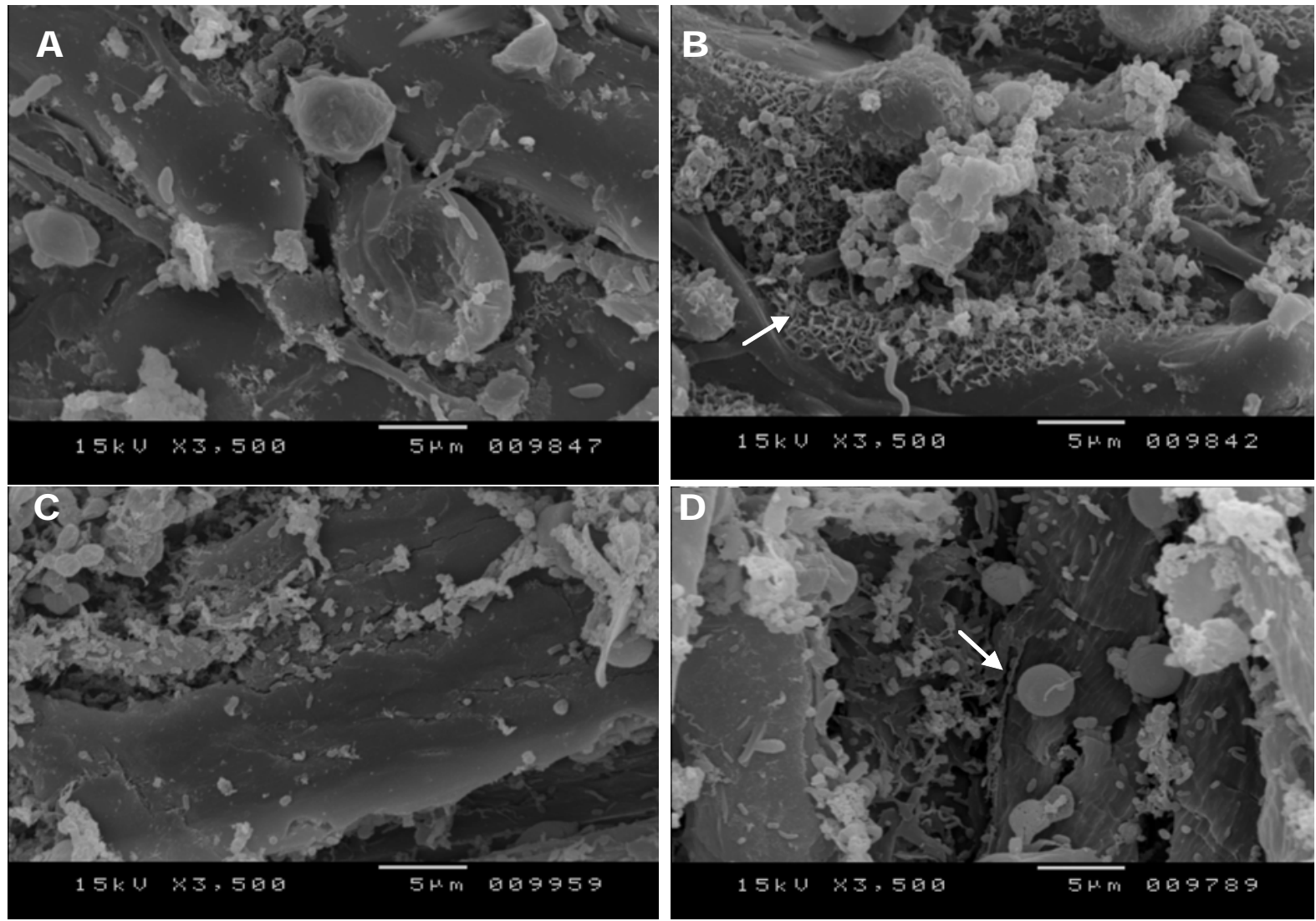

Figura 4 - Elétron-micrografias de varredura dos resíduos de degradação in situ do feno de Tifton 85 cortado aos 90 dias (FT90) sem a adição de enzimas ( $A$ e $C$ ) e com a adição de enzimas fibrolíticas (B e D). A e B - 3 horas de incubação; C e D - 48 horas de incubação. 5B ${ }^{\circledR}$ Célula do mesofilo. 5D ${ }^{\circledR}$ Fungo.

Figure 4 - Scanning electron micrograph of in situ degradation residues of Tifton 85 hay cutted at 90 days(H90) without enzymes addition (A and C) and with fibrolytic enzymes addition ( $B$ and $D$ ). $A$ and $B-3$ hours of incubation. $C$ and $D-48$ hours of incubation. $5 B \otimes$ mesophyll cell. $5 D \otimes F u n g i$. 

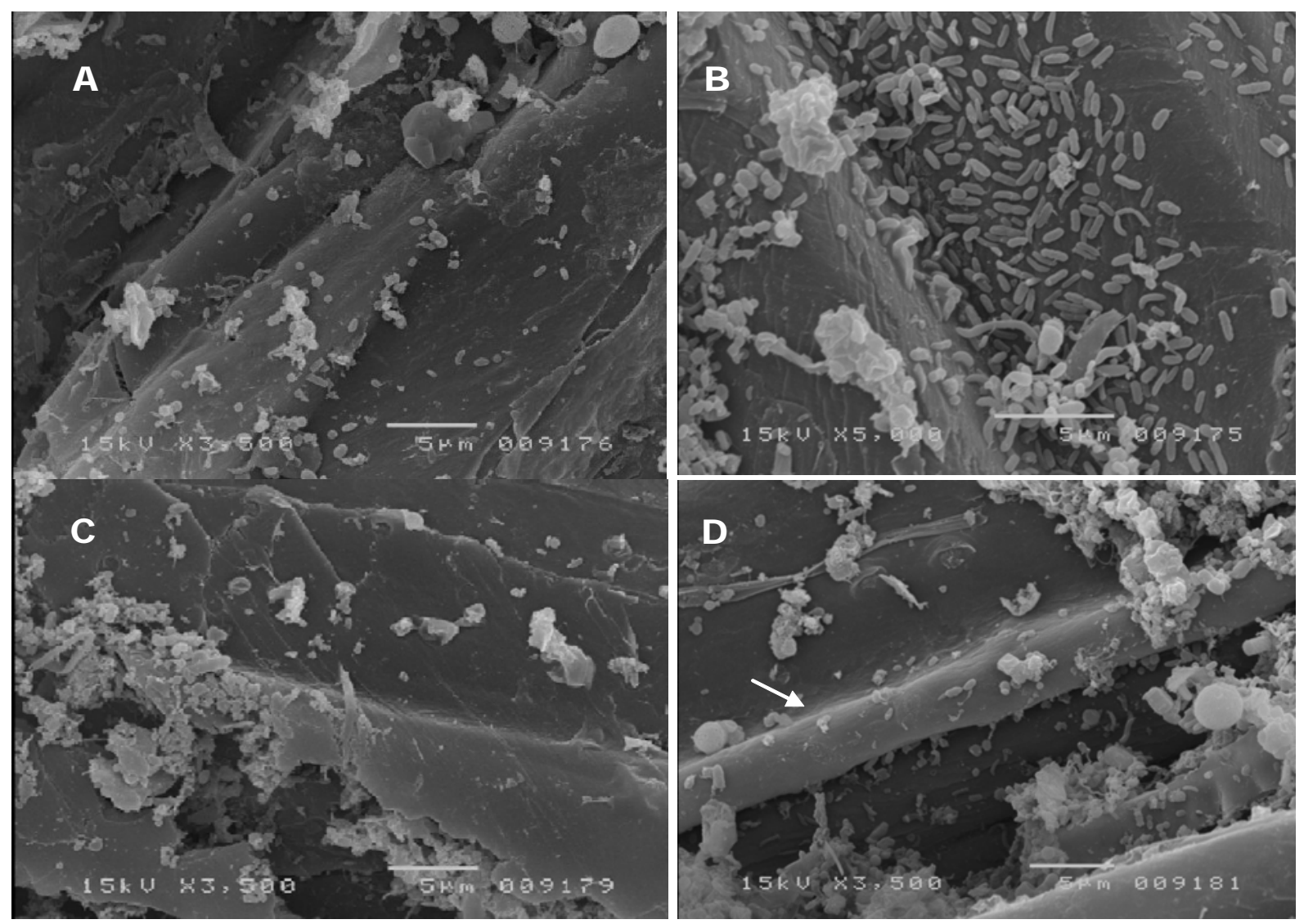

Figura 5 - Elétron-micrografias de varredura dos resíduos de degradação in situ do bagaço de cana-de-açúcar (BC) sem a adição de enzimas fibrolíticas ( $A$ e $C$ ) e com a adição de enzimas fibrolíticas (B e D). A e B - 48 horas de incubação; C e D - 72 horas de incubação. 6D ${ }^{\circledR}$ célula do esclerênquima.

Figure 5 - Scanning electron micrograph of in situ degradation residues of sugarcane bagasse (SB) without $(A$ and $C)$ and with fibrolytic enzymes $(B$ and D). $A$ and $B-48$ hours of incubation. $C$ and $D-72$ hours of incubation. $6 D \otimes$ sclerenchyma cell.

avaliada. Wallace et al. (2001) relataram que a suplementação com enzimas fibrolíticas na dose recomendada não causou efeito sobre a atividade das enzimas no fluido ruminal, sendo observado somente em concentrações maiores que as recomendadas pelo fabricante. Além disso, de acordo com Yang et al. (1999), a utilização de enzimas na nutrição de ruminantes pode ser compensatória somente se o suprimento enzimático presente no produto for compatível com a composição do alimento.

\section{Conclusões}

O efeito de enzimas fibrolíticas sobre os parâmetros de degradação ruminal variou em função do volumoso estudado, mas com efeito pouco expressivo em relação aos volumosos avaliados. O bagaço de cana apresentou maior resposta na degradação da parede celular com a adição das enzimas. As observações microscópicas dos resíduos revelaram aparente aumento na colonização bacteriana com a suplementação enzimática.

\section{Literatura Citada}

ASSIS, M.A.; SANTOS, G.T.; CECATO, U. et al. Degradabilidade in situ de gramíneas do gênero Cynodon submetidas ou não a adubação nitrogenadas. Acta Scientiarum, v.21, n.3, p.657-663, 1999.

AGRICULTURAL AND FOOD RESEARCH COUNCIL - AFRC. Technical committee on responses to nutrients: energy and protein requirements of ruminants. Wallingford: CAB International, 1995. 159p.

AGRICULTURAL RESEARCH COUNCIL - ARC. The nutrient requirements of ruminant livestock. London: Commonwealth Agricultural Bureaux, 1984. 184p.

AKIN, D.E. Histological and physiological factors affecting digestibility of roughages. Agronomy Journal, v.81, n.1, p.1725, 1989

AKIN, D.E.; BURDICK, D. Percentage of tissue types in tropical and temperate grass leaf blades and degradation of tissues by rumen microorganisms. Crop Science, v.15, n.5, p.661-668, 1975. 
BEAUCHEMIN, K.A.; RODE, L.M.; SEWALT, V.J.H. Fibrolytic enzymes increase fiber digestibility and growth rate of steers fed dry forages. Canadian Journal of Animal Science, v.75, p.641-644, 1995.

COUGHLAN, M.P. Cellulose degradation by fungi. In: FORGATY, W.I; KELLI, C.T. (Eds). Microbial enzymes and biotechnology. 2.ed. New York: Elsevier, 1990. p.1-36.

DEHORITY, B.A.; TIRABASSO, P.A. Effect of ruminal cellulolytic bacterial concentrations on in situ digestion of roughage cellulose. Journal of Animal Science, v.76, n.11, p.29052911, 1998.

DESCHAMPS, F.C. Degradabilidade ruminal da matéria seca e da proteína bruta de alguns alimentos utilizáveis na alimentação de ruminantes. Revista Brasileira de Zootecnia, v.23, n.6, p.899-909, 1994.

GILBERT, H.J.; HAZLEWOOD, G.P. Review article - Bacterial cellulases and xilanases. Journal General Microbiology, v.139, n.2, p.187-194, 1993.

HATFIELD, R.D. Structural polysaccharides in roughages and their degradability. Agronomy Journal, v.81, n.1, p.39-46, 1989.

HRISTOV, A.N.; McALLISTER, T.A.; CHENG, K.J. Intraruminal supplementation with increasing levels of exogenous polysaccharide-degrading eznymes: effects on nutrient digestion in cattle fed barley grain diets. Journal of Animal Science, v.78, n.2, p.477-487, 2000.

IIYAMA, K. Mechanisms for altering cell wall utilization. In: JUNG, H.G.; BUXTON, D.R.; HATFIELD, R.D. et al. (Eds). Forage cell wall structure and digestibility. 1.ed. Wisconsin: ASACSSA-SSSA, 1993. p.621-665.

ISHII, T. Structure and functions of feruylated polysaccharidesReview. Plant Science, v.127, p.111-127, 1997.

ÍTAVO, L.C.V.; SILVA, F.F.; CARDOSO, E.C. et al. Consumo, degradabilidade ruminal e digestibilidade aparente de fenos de gramíneas do gênero Cynodon e rações concentradas utilizando indicadores internos. Revista Brasileira de Zootecnia, v.31, n.2, p.1024-1032, 2002 (supl.).

JUNG, H.G.; DEETZ, D.A. Cell wall lignification and degradability. In: JUNG, H.G.; BUXTON, D.R.; HATFIELD, R.D. et al. (Eds). Forage cell wall structure and digestibility. 1.ed. Wisconsin: ASA-CSSA-SSSA, 1993. p.315-346.

LEMPP, B. Avaliações quantitativas, químicas, biológicas e anatômicas de lâminas de Panicum maximum Jacq. cv Aruana e Vencedor. Jaboticabal: Universidade Estadual Paulista, 1997. 162p. Tese (Doutorado em Produção Animal) Universidade Estadual Paulista, 1997.

McALlisteR, T.A.; OOSTING, S.J.; POPP, J.D. et al. Effect of exogenous enzymes on digestibility of barley silage and growth performance of feedlot cattle. Canadian Journal of Animal Science, v.79, n.3, p.353-360, 1999.
MEHREZ, A.Z.; ØRSKOV, E.R. A study of the artificial fibre bag technique for determining the digestibility of feeds in the rumen. Journal Agriculture Science, v.88, n.3, p.645-650, 1977.

MORGAVI, D.P.; NEWBOLD, C.J.; BEEVER, D.E. et al. Stability and stabilization of potential feed additive enzymes in rumen fluid. Enzyme and Microbial Technology, v.26, n.2-4, p.171-177, 2000.

NATIONAL RESEARCH COUNCIL - NRC. Nutrient requirements of dairy cattle. 7.ed. Washington, D.C.: National Academy Press, 2001. 381p.

$\varnothing$ RSKOV, E.R.; Mc DONALD, I. The estimation of protein degradability in the rumen from incubation measurements weighted according to rate of passage. Journal Agriculture Science, v.92, part 2, p.499-518, 1979.

RODE, L.M.; YANG, W.Z.; BEAUCHEMIN, K.A. Fibrolytic enzyme supplemented for dairy cows in early lactation. Journal of Dairy Science, v.82, n.10, p.2121-2126, 1999.

SANTOS, J.M. Microscopia de varredura aplicada às ciências biológicas. Jaboticabal: Funep, 1996. 56p.

STATISTICAL ANALYSIS SYSTEM - SAS. SAS/STAT user's guide: statistics. 8.ed. Version 6.11, Cary: 1997. v. 6, 943p.

SILVA, D.J.; QUEIROZ, A.C. Análise de alimentos: métodos químicos e biológicos. 3.ed. Viçosa, MG: Editora UFV, 2002. 235p.

SNIFFEN, C.J.; O’CONNOR, J.D.; van SOEST, P.J. et al. A net carbohydrate and protein system for evaluating cattle diets: II. Carbohydrate and protein availability. Journal of Animal Science, v.70, n.11, p.3562-3577, 1992.

VARGA, G.A.; KOLVER, E.S. Microbial and animal limitations to fiber digestion and utilization. Journal of Nutrition, v.127, n.5, p.819-823, 1997.

WALLACE, R.J.; WALLACE, S.J.A.; McKAIN, N. et al. Influence of supplementary fibrolytic enzymes on the fermentation of corn and grass silages by mixed ruminal microorganisms in vitro. Journal of Animal Science, v.79, n.7, p.1905-1916, 2001.

WILSON, J.R.; MERTENS, D.R. Cell wall accessibility and cell structure limitations to microbial digestion of roughage. Crop Science, v.35, n.1, p.251-259, 1995.

YANG, W.Z.; BEAUCHEMIN, K.A.; RODE, L.M. Effects of an enzyme feed additive on extent of digestion and milk production of lactating dairy cows. Journal of Dairy Science, v.82, n.2, p.391-403, 1999. 